\title{
Enraizamento de estacas de cultivares de guaranazeiro com adubação de plantas matrizes
}

\author{
Sônia Maria Figueiredo Albertino(1), Firmino José do Nascimento Filho(2), José Ferreira da Silva(1), \\ André Luiz Atroch ${ }^{(2)}$ e Anísia Karla de Lima Galvão(3)
}

\begin{abstract}
(1)Universidade Federal do Amazonas, Departamento de Produção Animal e Vegetal, Avenida General Rodrigo Octávio Jordão Ramos, no 3.000, Coroado I, CEP 69077-000 Manaus, AM. E-mail: sonialbertino@ufam.edu.br, jfsilva@ufam.edu.br (2)Embrapa Amazônia Ocidental, Caixa Postal 319, CEP 69010-970 Manaus, AM. E-mail: firmino.filho@cpaa.embrapa.br, andre.atroch@cpaa.embrapa.br (3)Instituto Federal de Educação, Ciência e Tecnologia do Amazonas, Avenida Cosme Ferreira, № 8.045, São José Operário, CEP 69085-015 Manaus, AM. E-mail: anisiagalvao@ifam.edu.br
\end{abstract}

Resumo - O objetivo deste trabalho foi avaliar o efeito da adubação das plantas matrizes no enraizamento de estacas de guaranazeiro. Utilizou-se o delineamento experimental inteiramente casualizado, em arranjo fatorial 6x2, com cinco cultivares e um genótipo de guaranazeiro, com ou sem adubação. A unidade experimental continha dez estacas com quatro repetições. A adubação foi aplicada após a poda de limpeza (janeiro), após a poda de frutificação (abril) e antes do início da floração (maio). Durante o enraizamento, as estacas foram mantidas em viveiros a $50 \%$ de irradiância e sob nebulização intermitente. Após 120 dias no viveiro, foram avaliadas as seguintes características: estacas enraizadas e mortas; comprimento das estacas; e o volume e a massa da matéria seca das raízes. A adubação das plantas matrizes aumentou em 11,15\% o percentual de enraizamento e reduziu em $11,05 \%$ a mortalidade das estacas. A adubação promoveu maior enraizamento nas cultivares BRS-Maués, BRS-CG882 e no genótipo CMU 381. Independentemente da cultivar, a adubação aumenta o número, o volume e a massa de matéria seca da raiz; porém, não tem influência no comprimento da raiz.

Termos para indexação: Paullinia cupana, nutrição mineral, propagação vegetativa.

\section{Rooting of guarana cultivar cuttings with fertilization of matrix plants}

\begin{abstract}
The objective of this work was to evaluate the effect of plant fertilization on the rooting of guarana cuttings. The experimental design was completely randomized in a $6 \times 2$ factorial arrangement, with five cultivars and one genotype of guarana, with or without fertilization. The experimental unit contained ten cuttings with four replicates. The fertilization was applied after pruning (January), after fruiting (April), and before the beginning of flowering (May). For rooting, the cuttings were kept in incubators at 50\% irradiance and under intermittent mist. After 120 days in the incubator, the following characteristics were evaluated: rooted and dead cuttings; cutting length; and volume and dry weight of roots. Plant fertilization increased rooting in $11.15 \%$, and reduced cutting mortality in $11.05 \%$. The fertilization promoted a greater rooting in the cultivars BRS-Maués, BRS-CG882 and in the genotype CMU 381. Irrespective of the cultivar, the fertilization increases the number, volume and weight of root dry matter; however, it has no influence on root length.
\end{abstract}

Index terms: Paullinia cupana, mineral nutrition, vegetative propagation.

\section{Introdução}

O guaranazeiro [Paullinia cupana var. sorbilis, (Mart.) Ducke] apresenta grande potencial socioeconômico para a agricultura no Estado do Amazonas. $\mathrm{O}$ contingente de mão de obra envolvido na produção e a crescente demanda pelo produto $\mathrm{o}$ caracterizam como importante alternativa para os setores agrícola e industrial do Estado. O cultivo comercial do guaraná tem sido incentivado por meio de práticas agrícolas e novas tecnologias geradas pelas pesquisas. $\mathrm{O}$ conhecimento sobre a cultura evoluiu consideravelmente nos últimos anos, mas muito ainda necessita ser feito.

Uma das dificuldades enfrentadas nos plantios tradicionais relaciona-se à baixa qualidade das mudas que, normalmente, são obtidas por sementes de material não selecionado (Arruda et al., 2007).

Portanto, a disponibilidade de material vegetal geneticamente uniforme, produtivo e de boa propagação

Pesq. agropec. bras., Brasília, v.47, n.10, p.1449-1454, out. 2012 
é fundamental para a expansão e melhoria da cultura do guaranazeiro no Amazonas. Para a manutenção dessas características, recomenda-se a produção de mudas por estaquia. Porém, este tipo de propagação depende de diversos fatores que determinam o desenvolvimento e a diferenciação das raízes, como o estado nutricional da planta matriz (Schawambach et al., 2005; Cruz et al., 2011).

A condição fisiológica da planta doadora de estacas, aliada à nutrição equilibrada, determinará a concentração de carboidratos, substâncias nitrogenadas, aminoácidos, auxinas, compostos fenólicos, entre outras substâncias promotoras do enraizamento (López-Bucio et al., 2002; Cunha et al., 2009a). Além disso, o estado nutricional da planta pode também atuar em sinergia com vários fatores que induzem o enraizamento e afetam o crescimento e vigor pós-propagação (López-Bucio et al., 2002).

O objetivo deste trabalho foi avaliar o efeito da adubação das plantas matrizes no enraizamento das estacas de guaranazeiro.

\section{Material e Métodos}

O experimento foi conduzido no campo experimental da Embrapa Amazônia Ocidental, no Km 29 da rodovia AM-010, no Município de Manaus, AM.

O estudo foi realizado no ano de 2009 e repetido em 2010, com as cultivares BRS-Amazonas, BRS-Maués, BRS-Mundurucânia, BRS-CG611, BRS-CG882 e o genótipo CMU 381, de guaranazeiro. O critério de seleção foi baseado no percentual de enraizamento de estacas das cultivares e do genótipo, classificados como de fácil enraizamento (acima de 80\%), enraizamento intermediário (em torno de $50 \%$ ) e de baixo enraizamento (13\% a 30\%) (Atroch et al., 2007). Esses materiais já foram avaliados e recomendados para plantio comercial no Estado do Amazonas, exceto o genótipo CMU 381, que ainda está em fase de avaliação para posterior lançamento como cultivar.

A adubação das plantas matrizes foi realizada em três aplicações anuais. A primeira, no final do período produtivo, logo após a poda de limpeza (janeiro); a segunda, após a poda de frutificação (abril) e a terceira, antes do início da floração (maio). Na primeira adubação foram aplicados $18 \mathrm{~g}$ por planta de N, $50 \mathrm{~g}$ por planta de $\mathrm{P}_{2} \mathrm{O}_{5}$ e 10 g por planta de $\mathrm{Mg}$; enquanto que na segunda, as plantas receberam $18 \mathrm{~g}$ por planta de N, 24 g por planta de $\mathrm{K}_{2} \mathrm{O}, 1$ g por planta de $\mathrm{B}$ e $\mathrm{Zn}$ e na terceira, foram aplicados $36 \mathrm{~g}$ por planta de $\mathrm{N}$ e 48 g por planta de K2O. Os adubos foram distribuídos ao redor da planta, na projeção da copa (Pereira, 2005).

As estacas foram coletadas de ramos herbáceos e sadios de plantas matrizes de guaranazeiro, nos anos de 2009 e de 2010. Cada estaca continha uma gema vegetativa e um par de folíolos, reduzido à metade na porção apical, para diminuir a transpiração. As estacas foram plantadas em sacos de polietileno, com dimensões de $23 \mathrm{~cm}$ de altura e $18 \mathrm{~cm}$ de largura, contendo $3 \mathrm{~kg}$ de substrato. O substrato utilizado foi uma mistura de terriço e areia, à proporção de 4:1 com mais $3 \mathrm{~kg}$ de superfosfato simples para cada metro cúbico da mistura (Pereira, 2005).

Para o enraizamento, as estacas foram mantidas em viveiros, à temperatura ambiente, com irradiância a $50 \%$ e nebulização intermitente controlada por uma balança de evaporação, em que a superfície dos meios folíolos recebia uma fina camada de água, distribuída uniformemente e em sincronia com a taxa de transpiração, para evitar a desidratação dos tecidos e garantir os processos fisiológicos do enraizamento.

Utilizou-se o delineamento inteiramente casualizado, em arranjo fatorial $6 \times 2$. Os tratamentos aplicados foram as cinco cultivares e o genótipo de guaranazeiro, com ou sem adubação das plantas matrizes, com quatro repetições e dez estacas por unidade experimental.

Após 120 dias no viveiro, as estacas foram separadas do substrato, por lavagem em água corrente e agitação manual, tendo-se coletado o sistema radicular intacto para anotação das seguintes características: estacas enraizadas e mortas, número de raízes por estaca, comprimento de raízes por estaca, volume e massa da matéria seca das raízes.

Todas as raízes foram cortadas rente ao ponto de inserção na estaca e, posteriormente, contadas e medidas. $\mathrm{O}$ volume foi medido pelo deslocamento de água, provocado pela introdução das raízes em uma proveta graduada. A massa de matéria seca foi obtida por meio da secagem das raízes em estufa a $70^{\circ} \mathrm{C}$ até a obtenção de massa constante.

Para efeito de análise, os dados em percentagem foram transformados em $(\mathrm{x}+0,5)^{0,5}$, e as médias foram comparadas pelo teste de Tukey, a 5\% de probabilidade. 


\section{Resultados e Discussão}

Houve efeito significativo da adubação sobre todas as variáveis, exceto sobre o comprimento das raízes nos anos de 2009 e de 2010 e sobre a análise conjunta (Tabela 1).

Houve efeito da cultivar nos dois anos avaliados e na análise conjunta. A interação adubação x cultivar foi significativa para todas as características avaliadas em 2009, à exceção do comprimento de raízes. Em 2010, apenas o número de raízes foi significativo, enquanto na análise conjunta, somente o comprimento de raízes não foi significativo (Tabela 1 ).

$\mathrm{O}$ fator ano influenciou significativamente $\mathrm{O}$ percentual de estacas enraizadas e o comprimento, volume e matéria seca das raízes. A interação ano $\mathrm{x}$ adubação $\mathrm{x}$ cultivar foi significativa apenas para estacas enraizadas (Tabela 1).

A percentagem de enraizamento foi superior no tratamento com adubação do genótipo CMU 381 e da cultivar BRS-Mundurucânia, em comparação ao tratamento sem adubação em 2009 (Tabela 2). Segundo classificação de Atroch et al. (2007), que agrupa os clones de guaranazeiro em quatro classes, conforme a capacidade de enraizamento das estacas, o percentual de enraizamento do genótipo CMU 381, no tratamento sem adubação, o classificaria como de difícil enraizamento. No entanto, a adubação elevou sua classificação para enraizamento mediano.

Entre as cultivares e genótipo, com adubação, também foi registrado o maior percentual de estacas enraizadas na 'BRS-Maués', que não diferiu do genótipo CMU 381 e da 'BRS-Mundurucânia' (Tabela 2). A percentagem de $81,25 \%$ de estacas enraizadas da 'BRS-Maués' foi superior aos valores encontrados por Arruda et al. (2007), que registraram $75,70 \%$ para a mesma cultivar.

No experimento realizado em 2010, houve a mesma tendência, com maior percentual de enraizamento em 'BRS-Maués' com adubação, que diferiu apenas de 'BRS-CG882' que apresentou o menor valor (Tabela 3). Apesar de a maioria das cultivares não ter

Tabela 1. Resumo da Anova para estacas enraizadas (EE), estacas mortas (EM), comprimento das raízes (CR), número de raízes (NR), volume das raízes (VR) e matéria seca das raízes (MSR) de cinco cultivares e de um genótipo de guaranazeiro, com ou sem adubação.

\begin{tabular}{|c|c|c|c|c|c|c|}
\hline \multirow[t]{2}{*}{ Fonte de variação } & \multicolumn{5}{|c|}{ Quadrado médio } & \multirow[b]{2}{*}{ MSR } \\
\hline & $\mathrm{EE}$ & EM & $\mathrm{CR}$ & NR & VR & \\
\hline \multicolumn{7}{|c|}{2009} \\
\hline Adubação & $43,0828 * *$ & $37,9051 * *$ & $23,8924^{\mathrm{ns}}$ & $338,7781 * *$ & $21,5271 * *$ & $0,4351 * *$ \\
\hline Cultivar & $24,7413 * *$ & $110,1063 * *$ & $204,9956^{* *}$ & $1505,1618 * *$ & $18,3507^{* *}$ & $0,4972 * *$ \\
\hline Adubação x cultivar & $10,9116^{* *}$ & $12,5464 * *$ & $3,7754^{\mathrm{ns}}$ & $75,5701^{*}$ & $3,8805^{* *}$ & $0,0621 * *$ \\
\hline Resíduo & 1,4927 & 2,4394 & 8,1430 & 26,3344 & 0,8407 & 0,0175 \\
\hline $\mathrm{CV}(\%)$ & 16,53 & 29,3275 & 25,81 & 41,20 & 31,84 & 30,59 \\
\hline \multicolumn{7}{|c|}{2010} \\
\hline Adubação & $34,7847 * *$ & $15,0792 *$ & $8,8130^{\mathrm{ns}}$ & $327,4453 * *$ & $20,1189^{* *}$ & $0,1696 * *$ \\
\hline Cultivar & $18,9858 * *$ & $109,0723 * *$ & $331,3773 * *$ & $485,3396^{* *}$ & $5,0181 * *$ & $0,0520^{*}$ \\
\hline Adubação x cultivar & $0,4836^{\mathrm{ns}}$ & $1,9923^{\mathrm{ns}}$ & $10,6754^{\mathrm{ns}}$ & $40,8984 *$ & $1,6802^{\mathrm{ns}}$ & $0,0482^{\mathrm{ns}}$ \\
\hline$\underline{\text { Resíduo }}$ & 1,4920 & 2,6200 & 10,9037 & 13,9123 & 0,7485 & 0,2162 \\
\hline $\mathrm{CV}(\%)$ & 15,76 & 32,14 & 25,25 & 40,81 & 29,63 & 31,09 \\
\hline \multicolumn{7}{|c|}{$2009-2010$} \\
\hline Ano & $6,9376^{*}$ & $1,2330^{\mathrm{ns}}$ & $118,9409 * *$ & $10,2628^{\mathrm{ns}}$ & $8,1909 * *$ & $0,8120 * *$ \\
\hline Adubação & $81,7033 * *$ & $49,7931 * *$ & $0,4979^{\text {ns }}$ & $447,1932 * *$ & $30,5714^{* *}$ & $0,3615 * *$ \\
\hline Cultivar & $23,5911 * *$ & $172,1410 * *$ & $512,9116^{* *}$ & $1138,5395 * *$ & $9,2704 * *$ & $0,3214 * *$ \\
\hline Ano x adubação & $5,5870^{\mathrm{ns}}$ & $7,0643^{\mathrm{ns}}$ & $19,4652^{\mathrm{ns}}$ & $30,8420^{\mathrm{ns}}$ & $0,6708^{\mathrm{ns}}$ & $0,0012^{\mathrm{ns}}$ \\
\hline Ano x cultivar & $14,4577 * *$ & $6,6608 *$ & $22,1183^{*}$ & $231,4402 * *$ & $9,9823 * *$ & $0,0949 * *$ \\
\hline Adubação x cultivar & $6,4636 * *$ & $10,4814 * *$ & $5,9160^{\mathrm{ns}}$ & $74,5203 * *$ & $3,4859 * *$ & $0,0799 * *$ \\
\hline Ano x adubação x cultivar & $5,0293 * *$ & $5,2806^{\mathrm{ns}}$ & $6,8268^{\mathrm{ns}}$ & $22,2285^{\mathrm{ns}}$ & $0,8433^{\mathrm{ns}}$ & $0,0323^{\mathrm{ns}}$ \\
\hline$\underline{\text { Resíduo }}$ & 1,4923 & 2,5426 & 9,7205 & 19,2361 & 0,7880 & 0,0198 \\
\hline $\mathrm{CV}(\%)$ & 16,06 & 30,95 & 25,41 & 41,91 & 30,57 & 30,85 \\
\hline
\end{tabular}

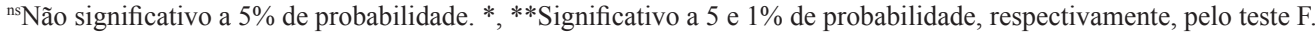


apresentado diferença significativa quanto à capacidade de enraizamento, tanto com adubação como sem adubação, vários autores registraram a existência de variabilidade genética para o caráter enraizamento de estacas entre cultivares de guaranazeiro (Arruda et al., 2007; Atroch et al., 2007).

A adubação também aumentou o percentual de estacas enraizadas de CMU 381, 'BRS-Maués' e 'BRS-CG882', em comparação ao tratamento sem adubação (Tabela 3). O efeito positivo da adubação tornou-se mais evidente no genótipo CMU 381, cujos percentuais de enraizamento mostraram diferenças significativas nos dois anos de estudo (Tabelas 2 e 3).

Quanto ao percentual de estacas mortas, o maior valor foi registrado para 'CMU 381' sem adubação. No entanto, com adubação, essa percentagem foi reduzida em torno de 50\% (Tabela 2). No segundo experimento, realizado em 2010, também houve diferença significativa quanto à adubação para a mesma variável e genótipo, porém a amplitude de variação foi menor (Tabela 3). A cultivar que apresentou a segunda maior mortalidade de estacas no experimento em 2009, foi BRS-CG882, que não diferiu das outras cultivares quanto à adubação (Tabela 2).

Tabela 2. Percentagem de estacas enraizadas e estacas mortas de cinco cultivares e um genótipo (CMU 381) de guaranazeiro, com ou sem adubação ${ }^{(1)}$.

\begin{tabular}{|c|c|c|c|}
\hline \multirow[t]{2}{*}{ Cultivares/genótipo } & \multicolumn{2}{|c|}{ Adubação (2009) } & \multirow{2}{*}{$\begin{array}{l}\text { Média de } \\
\text { cultivares }\end{array}$} \\
\hline & Com & Sem & \\
\hline & \multicolumn{3}{|c|}{ Estacas enraízadas (\%) } \\
\hline BRS-Amazonas & $54,37 \mathrm{cdA}$ & $56,87 \mathrm{bcA}$ & $55,62 \mathrm{bc}$ \\
\hline CMU 381 & $65,00 \mathrm{abcA}$ & $28,75 \mathrm{~dB}$ & $46,87 \mathrm{c}$ \\
\hline BRS-Mundurucânia & $75,62 \mathrm{abA}$ & $51,25 \mathrm{bcB}$ & $63,43 b$ \\
\hline BRS-CG611 & $59,37 \mathrm{cdA}$ & $58,75 \mathrm{abA}$ & $59,06 \mathrm{~b}$ \\
\hline BRS-Maués & $81,25 \mathrm{aA}$ & $73,75 \mathrm{aA}$ & $77,50 \mathrm{a}$ \\
\hline$\underline{\text { BRS-CG882 }}$ & $45,62 \mathrm{dA}$ & $45,00 \mathrm{cdA}$ & $45,31 \mathrm{c}$ \\
\hline \multirow[t]{2}{*}{ Médias de adubação } & $63,54 \mathrm{~A}$ & 52,39B & 57,96 \\
\hline & \multicolumn{3}{|c|}{ Estacas mortas (\%) } \\
\hline BRS-Amazonas & $12,50 \mathrm{dA}$ & $6,25 \mathrm{dA}$ & $9,35 \mathrm{~d}$ \\
\hline CMU 381 & $34,37 \mathrm{abB}$ & $70,00 \mathrm{aA}$ & $52,18 \mathrm{a}$ \\
\hline BRS-Mundurucânia & $24,37 \mathrm{bcB}$ & $48,12 \mathrm{bA}$ & $36,25 b$ \\
\hline BRS-CG611 & $33,75 \mathrm{bA}$ & $37,50 \mathrm{bcA}$ & $35,62 b$ \\
\hline BRS-Maués & $15,00 \mathrm{cdA}$ & $23,12 \mathrm{cA}$ & $19,06 \mathrm{c}$ \\
\hline BRS-CG882 & $53,75 \mathrm{aA}$ & $55,00 \mathrm{abA}$ & $54,37 \mathrm{a}$ \\
\hline Médias de adubação & $28,95 \mathrm{~B}$ & $40,00 \mathrm{~A}$ & 34,47 \\
\hline
\end{tabular}

O genótipo CMU 381 mostrou elevada influência da adubação em seu potencial rizogênico, com redução da mortalidade das estacas e aumento da percentagem de enraizamento, quando as plantas matrizes foram adubadas. No entanto, isto não foi verificado na cultivar BRS-CG882. Para Atroch et al. (2007), este fato pode ser atribuído à existência de um forte componente genético quanto à capacidade e habilidade para o enraizamento entre as diferentes cultivares de guaranazeiro.

Tabela 3. Percentagem de estacas enraizadas e mortas de cinco cultivares e um genótipo (CMU 381) de guaranazeiro, com ou sem adubação ${ }^{(1)}$.

\begin{tabular}{|c|c|c|c|}
\hline \multirow[t]{2}{*}{ Cultivares/genótipo } & \multicolumn{2}{|c|}{ Adubação (2010) } & \multirow{2}{*}{$\begin{array}{l}\text { Média de } \\
\text { cultivares }\end{array}$} \\
\hline & Com & Sem & \\
\hline & \multicolumn{3}{|c|}{ Estacas enraízadas (\%) } \\
\hline BRS-Amazonas & $70,41 \mathrm{aA}$ & $62,50 \mathrm{aA}$ & $66,45 \mathrm{a}$ \\
\hline CMU 381 & $70,43 \mathrm{aA}$ & $56,95 \mathrm{aB}$ & $64,16 a$ \\
\hline BRS-Mundurucânia & $69,13 \mathrm{a} \mathrm{A}$ & $60,77 \mathrm{aA}$ & $65,04 \mathrm{a}$ \\
\hline BRS-CG611 & $68,75 \mathrm{aA}$ & $62,50 \mathrm{aA}$ & $65,62 \mathrm{a}$ \\
\hline BRS-Maués & $76,25 \mathrm{aA}$ & $64,17 \mathrm{aB}$ & $70,34 a$ \\
\hline BRS-CG882 & $53,26 \mathrm{bA}$ & $45,41 \mathrm{bB}$ & $49,25 \mathrm{~b}$ \\
\hline \multirow[t]{2}{*}{ Médias de adubação } & $68,12 \mathrm{~A}$ & $58,70 \mathrm{~B}$ & 63,47 \\
\hline & \multicolumn{3}{|c|}{ Estacas mortas (\%) } \\
\hline BRS-Amazonas & $6,66 \mathrm{cA}$ & $6,25 \mathrm{cA}$ & $6,45 c$ \\
\hline CMU 381 & 25,91abB & $42,55 \mathrm{abA}$ & $33,65 b$ \\
\hline BRS-Mundurucânia & $28,69 \mathrm{abA}$ & $37,73 \mathrm{abA}$ & $33,21 b$ \\
\hline BRS-CG611 & $29,58 \mathrm{abA}$ & $30,83 \mathrm{bA}$ & $30,20 \mathrm{~b}$ \\
\hline BRS-Maués & $21,66 \mathrm{bA}$ & $31,86 \mathrm{abA}$ & $26,66 \mathrm{~b}$ \\
\hline BRS-CG882 & $44,91 \mathrm{aA}$ & $52,50 \mathrm{aA}$ & $48,78 \mathrm{a}$ \\
\hline Médias de adubação & $26,09 \mathrm{~B}$ & $33,34 \mathrm{~A}$ & 29,68 \\
\hline
\end{tabular}

Tabela 4. Percentagem de estacas enraizadas e mortas de guaranazeiro, independentemente da cultivar, com ou sem adubação.

\begin{tabular}{|c|c|c|c|}
\hline \multirow[t]{2}{*}{ Ano } & \multicolumn{2}{|c|}{ Adubação (2009/2010) } & \multirow{2}{*}{$\begin{array}{c}\text { Média de } \\
\text { anos }\end{array}$} \\
\hline & Com & Sem & \\
\hline & \multicolumn{3}{|c|}{ Estacas enraízadas (\%) } \\
\hline 2009 & $63,54 \mathrm{aA}$ & $52,39 \mathrm{bB}$ & $57,96 b$ \\
\hline 2010 & $68,12 \mathrm{aA}$ & $58,70 \mathrm{aB}$ & $63,47 \mathrm{a}$ \\
\hline \multirow[t]{2}{*}{ Média de adubação } & $66,26 \mathrm{~A}$ & $56,17 \mathrm{~B}$ & 61,22 \\
\hline & \multicolumn{3}{|c|}{ Estacas mortas (\%) } \\
\hline 2009 & $28,95 \mathrm{bB}$ & $40,00 \mathrm{aA}$ & $34,47 \mathrm{a}$ \\
\hline 2010 & $26,09 \mathrm{aB}$ & $33,34 \mathrm{aA}$ & $29,68 \mathrm{a}$ \\
\hline Média de adubação & $27,53 \mathrm{~B}$ & $36,07 \mathrm{~A}$ & 31,63 \\
\hline
\end{tabular}


$\mathrm{Na}$ análise conjunta do percentual de estacas enraizadas e mortas, nos dois anos de experimento, o efeito da adubação sobre o enraizamento das estacas foi significativo tanto em 2009 quanto em 2010, com valores de enraizamento superiores a $60 \%$ nas estacas retiradas de matrizes adubadas, enquanto a ausência de adubação resultou em maior mortalidade das estacas (Tabela 4).

Tais resultados indicam que a formação de raízes, em estacas de determinadas cultivares de guaranazeiro, é dependente dos níveis iniciais de nutrientes dentro da porção da estaca onde as raízes são formadas.

Tabela 5. Médias de comprimento da raiz, número de raízes, volume das raízes e matéria seca das raízes de cinco cultivares e um genótipo (CMU 381) de guaranazeiro, com ou sem adubação ${ }^{(1)}$.

\begin{tabular}{|c|c|c|c|}
\hline \multirow[t]{2}{*}{ Cultivares/genótipo } & \multicolumn{2}{|c|}{ Adubação (2009/2010) } & \multirow{2}{*}{$\begin{array}{l}\text { Média de } \\
\text { cultivares }\end{array}$} \\
\hline & Com & Sem & \\
\hline & \multicolumn{3}{|c|}{ Comprimento da raíz $(\mathrm{cm})$} \\
\hline BRS-Amazonas & $14,21 \mathrm{aA}$ & $14,97 \mathrm{aA}$ & $14,59 \mathrm{a}$ \\
\hline CMU 381 & $16,03 \mathrm{aA}$ & $15,77 \mathrm{aA}$ & $15,90 \mathrm{a}$ \\
\hline BRS-Mundurucânia & $8,75 \mathrm{cA}$ & $9,06 \mathrm{cA}$ & $8,91 \mathrm{c}$ \\
\hline BRS-CG611 & $11,88 \mathrm{bA}$ & $11,58 \mathrm{bA}$ & $11,73 b$ \\
\hline BRS-Maués & $11,71 \mathrm{bA}$ & $11,64 \mathrm{bA}$ & $11,68 b$ \\
\hline BRS-CG882 & $11,20 \mathrm{bA}$ & $10,32 \mathrm{bcA}$ & $10,76 b$ \\
\hline \multirow[t]{2}{*}{ Média de adubação } & $12,30 \mathrm{~A}$ & $12,22 \mathrm{~A}$ & 12,26 \\
\hline & \multicolumn{3}{|c|}{ Número de raízes } \\
\hline BRS-Amazonas & $5,42 \mathrm{cA}$ & $4,04 \mathrm{cA}$ & $4,73 \mathrm{c}$ \\
\hline CMU 381 & $11,14 \mathrm{bA}$ & $7,92 \mathrm{bB}$ & $9,53 b$ \\
\hline BRS-Mundurucânia & $18,80 \mathrm{aA}$ & $13,12 \mathrm{aB}$ & $15,96 \mathrm{a}$ \\
\hline BRS-CG611 & $8,43 \mathrm{bA}$ & $8,22 \mathrm{bA}$ & $8,33 b$ \\
\hline BRS-Maués & $9,37 \mathrm{bA}$ & $9,01 \mathrm{bA}$ & $9,19 b$ \\
\hline BRS-CG882 & $16,63 \mathrm{aA}$ & $13,42 \mathrm{aB}$ & $15,02 \mathrm{a}$ \\
\hline \multirow[t]{2}{*}{ Média de adubação } & 11,63 & $9,29 \mathrm{~B}$ & 10,46 \\
\hline & \multicolumn{3}{|c|}{ Volume das raízes $(\mathrm{mL})$} \\
\hline BRS-Amazonas & $2,69 \mathrm{cdA}$ & $2,58 \mathrm{aA}$ & $2,64 \mathrm{bc}$ \\
\hline CMU 381 & $3,57 \mathrm{abA}$ & $2,41 \mathrm{aB}$ & $2,99 \mathrm{ab}$ \\
\hline BRS-Mundurucânia & $3,68 \mathrm{aA}$ & $2,83 \mathrm{aB}$ & $3,26 \mathrm{a}$ \\
\hline BRS-CG611 & $2,44 \mathrm{dA}$ & $2,46 \mathrm{aA}$ & $2,45 \mathrm{c}$ \\
\hline BRS-Maués & $2,72 \mathrm{cdA}$ & $2,33 \mathrm{aA}$ & $2,75 \mathrm{bc}$ \\
\hline BRS-CG882 & $3,68 \mathrm{aA}$ & $2,94 \mathrm{aB}$ & $3,31 \mathrm{a}$ \\
\hline \multirow[t]{2}{*}{ Média de adubação } & $3,19 \mathrm{~A}$ & $2,61 \mathrm{~B}$ & 2,90 \\
\hline & \multicolumn{3}{|c|}{ Matéria seca das raízes $(\mathrm{g})$} \\
\hline BRS-Amazonas & $0,41 \mathrm{cdA}$ & $0,37 \mathrm{bA}$ & $0,39 \mathrm{c}$ \\
\hline CMU 381 & $0,55 \mathrm{bA}$ & $0,42 \mathrm{abB}$ & $0,49 b$ \\
\hline BRS-Mundurucânia & $0,48 \mathrm{bcA}$ & $0,39 \mathrm{bB}$ & $0,44 \mathrm{bc}$ \\
\hline BRS-CG611 & $0,38 \mathrm{dA}$ & $0,40 \mathrm{bA}$ & $0,39 \mathrm{c}$ \\
\hline BRS-Maués & $0,45 \mathrm{cdA}$ & $0,43 \mathrm{abA}$ & $0,44 b c$ \\
\hline BRS-CG882 & $0,64 \mathrm{aA}$ & $0,50 \mathrm{aB}$ & $0,57 \mathrm{a}$ \\
\hline Média de adubação & $0,49 \mathrm{~A}$ & $0,42 \mathrm{~B}$ & 0,45 \\
\hline
\end{tabular}

(1)Médias seguidas por letras iguais, minúsculas nas colunas e maiúsculas nas linhas, não diferem entre si, pelo teste de Tukey, a $5 \%$ de probabilidade.
Em estudos sobre a dinâmica de nutrientes e enraizamento de estacas de Celtis sp., observou-se que as maiores concentrações de nutrientes nessas estacas resultaram em aumento das percentagens de enraizamento (Dias et al., 2002).

O comprimento médio das raízes não foi influenciado pela adubação das plantas matrizes (Tabela 5). No entanto, entre cultivares e genótipo, a BRS-Amazonas e o CMU 381 apresentaram os maiores comprimentosc sem e com adubação.

Quanto ao número, volume e peso da matéria seca das raízes, o efeito da adubação foi significativo para o genótipo CMU 381 e para as cultivares BRS-Mundurucânia e BRS-CG882 (Tabela 5). Tal resultado mostra a exigência nutricional desses materiais para a formação de seu sistema radicular. O maior número de raízes por estaca foi encontrado na 'BRS-Mundurucânia', que não diferiu da 'BRS-CG882'. Para estas duas cultivares, também foram registrados os maiores volumes de raízes.

A massa média da matéria seca das raízes da 'BRS-CG882' adubada foi superior às das outras cultivares (Tabela 5). No entanto, na ausência de adubação, 'BRS-CG882' não diferiu da 'BRS-Maués' nem do genótipo CMU 381.

Um eficiente sistema radicular é caracterizado não só pela quantidade de raízes formadas, mas também pelo tamanho, volume e massa de matéria seca de suas raízes. Estes atributos justificam o uso de adubação nas plantas matrizes, como forma de atender às necessidades nutricionais das cultivares, que responderam bem à adubação, o que resultou na melhoria da qualidade de seu sistema radicular.

Segundo Cunha et al. (2009b), a nutrição mineral é considerada fator determinante para a predisposição ao enraizamento, o que desencadeia respostas morfogenéticas das plantas, tais como a formação, a quantidade, o comprimento e a densidade de raízes adventícias.

\section{Conclusões}

1. A adubação de plantas matrizes de guaranazeiro aumenta o percentual de enraizamento e reduz a mortalidade das estacas.

2. A adubação aumenta o número, o volume e a massa de matéria seca das raízes de guaranazeiro. 


\section{Referências}

ARRUDA, M.R. de; PEREIRA, J.C.R.; MOREIRA,A.; TEIXEIRA, W. Enraizamento de estacas herbáceas de guaranazeiro em diferentes substratos. Ciência e Agrotecnologia, v.31, p.236-241, 2007.

ATROCH, A.L.; CRAVO, M. da S.; SANTOS, J.A. dos. Enraizamento de estacas de clones de guaranazeiro tratados com ácido indol-3-butírico (AIB). Revista de Ciências Agrárias, v.47, p.103-111, 2007.

CRUZ, C.A.F. e; PAIVA, H.N. de; CUNHA, A.C.M.C.M. da; NEVES, J.C.L. Macronutrientes na produção de mudas de canafístula em Argissolo Vermelho-Amarelo da região da Zona da Mata, MG. Ciência Florestal, v.21, p.445-457, 2011.

CUNHA, A.C.M.C.M. da; PAIVA, H.N. de; LEITE, H.G.; BARROS, N.F. de; LEITE, F.P. Influência do estado nutricional de minicepas no enraizamento de miniestacas de eucalipto. Revista Árvore, v.33, p.607-615, 2009a.
CUNHA, A.C.M.C.M. da; PAIVA, H.N. de; XAVIER, A.; OTONI, W.C. Papel da nutrição mineral na formação de raízes adventícias em plantas lenhosas. Pesquisa Florestal Brasileira, n.58, p.35-49, 2009 b.

DIAS, H.C.T.; ANDRADE, L.A. de; MATIAS, S.S.M.; SATO, A.Y.; SOUZA, A.P. de. Dinâmica de nutrientes e enraizamento de estacas de Celtis sp. Revista Árvore, v.26, p.7-12, 2002.

LÓPEZ-BUCIO, J.; HERNÁNDEZ-ABREU, E.; SÁNCHEZ-CALDERÓN, L.; NIETO-JACOBO, M.F.; SIMPSON, J.; HERRERA-ESTRELLA, L. Phosphate availability alters architecture and causes changes in hormone sensitivity in the Arabidopsis root system. Plant Physiology, v.129, p.244-256, 2002.

PEREIRA, J.C.R. (Ed.). Cultura doguaranazeiro no Amazonas. 4. ed. Manaus: Embrapa Amazônia Ocidental, 2005. 40p. (Embrapa Amazônia Ocidental. Sistemas de produção, 2).

SCHAWAMBACH, J.; FADANELLI, C.; FETT-NETO, A.G. Mineral nutrition and adventitious rooting in microcuttings of Eucalyptus globulus. Tree Physiology, v.25, p.487-494, 2005.

Recebido em 28 de fevereiro de 2012 e aprovado em 23 de agosto de 2012 